\title{
Efficiency of inclusive physical education lessons for schoolchildren with minor deviations in health
}

\author{
Bodnar Ivanna, Prystupa Eugene
}

Lviv State University of Physical Culture

\section{Abstract}

Introduction: Some contradictory data regarding the effects of inclusive physical education were revealed. The purpose of the research is to determine the efficiency of inclusive physical education for schoolchildren of I-III health groups of middle school age on the base of indices of complaints connected with health conditions, mental development, and physical activity.

Material and methods: theoretical knowledge, sociological, educational, psycho diagnostics (degree of anxiety by Spielberger - Hanin, HAM: health, activity, mood) auto timing of motor activity (the Framingham method). The experimental group consisted of schoolchildren who were studying at secondary schools in inclusive terms - in these schools physical culture lessons for schoolchildren of I-III health groups were held both for practically healthy children and children with minor deviations in health status (with differentiation of tasks depending on the needs and capabilities of each child). The control group consisted of schoolchildren from the schools where the physical education lessons were conducted separately (segregatively) for schoolchildren of base, preparatory, and special medical groups. The study involved 1414 pupils of secondary school age (5-9 grades). The experimental group consisted of 694 individuals (320 girls and 374 boys) - the control one -720 individuals ( 332 girls and 388 boys).

Results: The trend toward the decreasing of the number of schoolchildren complaining of health condition with years of training in the experimental group confirmed the higher efficiency of inclusive physical education. Inclusive physical training lessons are less psychologically traumatic than segregative ones because schoolchildren from different medical groups in such terms suffer from the high level of anxiety less; low, often subjective, self-estimation, well-being, activity and mood are significantly higher. Positive changes in mental health are observed in the most tangible inclusive environment among schoolchildren with health deviations. Intensive everyday household physical activity and sports confirm the benefits of inclusive physical education.

Conclusions: A high efficiency inclusive physical education student of I-III health groups was proved.

Key words: physical education, inclusion, anxiety, physical activity

e-mail: ivannabodnar@ukr.net 


\section{Introduction}

The upward trend in the number of students with deviations in health is generally observed in the postSoviet area. Most often schoolchildren suffer from sight impairment [1-4], disabilities of musculoskeletal system (MSS) $[2,4]$, the boundary neuro and psycho disorders $[2,3]$. It is known that health deterioration in terms of one generation is due to an increase in the proportion of children living in the state of "the third condition", i.e. between norm and pathology [5]. Early detection of the disease or clarification of pre-nosological health deteriorating factors in secondary school age students of different demographic and medical groups nowadays is considered as a progressive approach to solving the problem of public health improving. The observations [6] show that even light but long-term pre-nosological conditions can limit physical abilities, violate intellectual function, worsen social self-adaptation of the individual, and distort the process of a person's identity formation. Minor health deviations can impact the whole individual, in particular his/her communication function which in its turn dramatically impede social adaptation of children. Some features of the mental state of children with health disorders can lead to the desire to be invisible in the classroom. This brings about low activity during the Physical Education lessons and at extra curriculum time and therefore increases their lagging behind from practically healthy children in a number of physical development and physical fitness indices [6].

The experts insist on early prevention of disease through the school system, since the school is the primary social institution responsible for the promotion of health [7-9]. One of the options to improve the schoolchildren's health may be the inclusive physical education (PE). Conducting inclusive physical education lesson (PE) contributes to positive changes in indices of schoolchildren with health deviations, healthy classmates and teachers, that is - all participants of educational process.

Inclusive PE provides common lessons for schoolchildren of all five (I -V) groups in terms of a secondary school (SS). The introduction in a regular school that aspires to be inclusive shared PE lessons for pupils of I- III health groups (BMG, PGP and SMG) indicators of physical and mental development, physical fitness of which don't differ significantly, can help prepare to some innovations.

As some researchers expressed contradictory data regarding the effects of inclusive $\mathrm{PE}$ in practice, it is important to determine the efficacy of inclusive PE for schoolchildren with minor health deviations (I- III group health). Defining of the efficiency of inclusive
PE for students of the I-III groups can contribute to the identification of its "strong" and "weak" sides, which will efficiently carry out the process of inclusive PE for pupils of BMG, PMG and SMG in terms of a single educational process for effective adaptation to life in society and full participation of the natural potential of all its citizens and to improve the process of inclusive education implementing in the country in accordance with international treaties on human rights.

\section{Material and methods}

The purpose is to determine the efficiency of inclusive PE for schoolchildren of I-III groups of secondary school age according to the indices of complaints of health, mental development and motor activity (MA) features.

1. To determine differences in the impact of inclusive and segregational ways of PE on pre-nosological indices (complaints of health);

2. To identify the outcomes of inclusive and segregational methods of PE on mental development of schoolchildren of I-III health groups.

3. To compare the impact of inclusive PE on the amount of MA of pupils of different age and sex groups.

Methods: theoretical knowledge, sociological method (survey), teaching method (experiment), psycho diagnostic (method for determining the degree of anxiety Spielberger - Hanin, HAM: health, activity, mood) auto timing daily MA (Framingham method). According to the Framingham children independently measured timing for one day in a week (Tuesday, Wednesday or Thursday in December - February) and completed registration card developed for a pupil's MA. The individual indices of MA (in points) and energy costs were calculated. The experimental group (EG) included the schoolchildren who had studied in the school in inclusive terms in these schools PE lessons for pupils of I-III health groups were conducted both for practically healthy children and children with minor health deviations (with differentiation / individualization of tasks depending on the needs and capabilities of each child). Schoolchildren who were placed by doctors into the 1st health group for PE lessons belonged to BMG, group 2 - to PMG, 3rd one - to SMG (Table 1). A control group (CG) consisted of secondary school pupils where PE lessons were conducted separately (segregationaly) for basic, preparatory and a special medical group. Nine schools (none of them was inclusive) were involved in the experiment. The study involved 1414 pupils of secondary school age (5-9 classes). The number of students in EG was 694 persons, among them there were 320 girls and 374 boys. CG consisted of 720 people, including 332 girls and 388 boys. 


\section{Results and discussion}

We have revealed (Table 2) that EG pupils complain about health troubles more often than $\mathrm{CG}$ pupils. Practically all of our proposed variants of health complaints (except for one - complaints about the difficulty of physical activity performance for the last time) the number of schoolchildren with complaints was higher among those who were educated in inclusive terms of PE. Perhaps the reason is in their higher sensitivity to
Some disorders in the pupils' neuropsychiatric field can be explained by the unfavorable morpho-functional features of the central nervous system (CNS) at the present age period, resulting endemic iodine deficiency, which can lead to a tense functioning of the CNS, and increased vulnerability caused by the intensification of the educational process, increased demands of school and family psychological atmosphere in the classroom, defects of education, the presence of systemic diseases and original in this age hormonal changes. That is

Tab. 1. Characteristics of the schoolchildren of I-III health groups

\begin{tabular}{|l|l|l|l|}
\hline \multirow{2}{*}{\multicolumn{1}{|c|}{ Indicators }} & \multicolumn{1}{|c|}{ practically healthy } & \multicolumn{1}{c|}{ Schoolchildren } \\
\cline { 2 - 4 } & \multicolumn{1}{|c|}{$1^{\text {st }}$ health group } & \multicolumn{1}{c|}{$2^{\text {nd }}$ health group } & \multicolumn{1}{c|}{$3^{\text {rd }}$ health group } \\
\hline $\begin{array}{l}\text { Characteristics of } \\
\text { the health (medical } \\
\text { characteristics) }\end{array}$ & $\begin{array}{l}\text { There are no chronic medical } \\
\text { conditions that do not hurt } \\
\text { or rarely suffered during } \\
\text { the observations, which are } \\
\text { appropriate to the age of the } \\
\text { physical and neuro-psychical } \\
\text { development }\end{array}$ & $\begin{array}{l}\text { Healthy with morphological and } \\
\text { functional abnormalities and } \\
\text { reduced resistance }\end{array}$ & $\begin{array}{l}\text { Patients in a state of compensation } \\
\text { (balancing, alignment of impaired } \\
\text { functions of the body. Disease is } \\
\text { characterized by favorable course, } \\
\text { slight complications, time - brief, } \\
\text { therapeutic effects - minimum }\end{array}$ \\
\hline $\begin{array}{l}\text { Characteristics of } \\
\text { medical groups } \\
\text { (pedagogical } \\
\text { characteristics) }\end{array}$ & $\begin{array}{l}\text { Basic Medical Group (BMG) } \\
\text { - good health, as well as minor } \\
\text { deviations in health status } \\
\text { (a small loss of hearing, vision, } \\
\text { tuberculosis intoxication, high } \\
\text { blood pressure, etc.) with } \\
\text { sufficient physical development } \\
\text { and physical fitness }\end{array}$ & $\begin{array}{l}\text { Preparatory Medical Group } \\
\text { (SGP) - convalescents and those } \\
\text { with minor deviations in health } \\
\text { status or practically healthy } \\
\text { with insufficient physical } \\
\text { development and poor physical } \\
\text { fitness }\end{array}$ & $\begin{array}{l}\text { Special Medical Group (SMG) } \\
\text { absence of threat and aggravation } \\
\text { under the influence of stress, } \\
\text { the absence of severe functional } \\
\text { deficiency sick organ or system, } \\
\text { retaining only some clinical } \\
\text { signs of the disease, a good } \\
\text { general state of health, the lack } \\
\text { of complaints, favorable response } \\
\text { to loadings, achieved through } \\
\text { exercises. }\end{array}$ \\
\hline
\end{tabular}

themselves and produced habit to listen to their feelings or symptoms that developed under the influence of common PE lessons due to the need to care for children with insufficient mobility and to empathize with them. EG pupils significantly more often complained about the hardships connected with muscular-skeleton system $(7.0 \%, \mathrm{p}<0.05)$ and sight discomfort $(5.8 \%, \mathrm{p}<0.05)$ than $\mathrm{CG}$ pupils. The reasons were not cleared out as it is necessary to conduct narrowly focused research.

It should be noted that with age, the number of schoolchildren with symptoms of pre-disease (prenosological) state of EG pupils tends to decrease (except for pupils with complaints about deficiencies in muscular-skeleton system). While CG pupils by all parameters tended to increase ones with complaints about poor health. Number of schoolchildren who complained of unwarranted changes in mood, anxiety and irritability in $\mathrm{CG}$ among practically healthy schoolchildren - BMG $(17.3 \%, \mathrm{p}<0.01)$ is significantly higher than in EG. One of the factors that could have caused frustration in students who studied in terms of segregational PE lessons probably serves as the mere break with friends. a lot of possible reasons are available, but it is especially anxiously that most symptoms of pre-disease state of secondary school age children were deviations in the nervous system, which in the future may lead to susceptibility to affective examined failures and neurotic and psychosomatic disorders. This fact prompted us to conduct the psycho-diagnostic research.

Based on the results of psycho-diagnostic the data can be drawn about the existence of a somewhat lower level of emotional reaction to a stressful situation (situational anxiety) in the EG pupils, as a whole the number among EG pupils with low situational anxiety was slightly higher (27 versus 23) than in CG. In CG pupils with high levels of personal anxiety in different age and sex subgroups was significantly $(\mathrm{p}<0.05)$ higher than in the EG (23 and 15 respectively); which serves as a testament to the perception of students enrolled in segregational PE conditions, more diverse situations which are dangerous to self-esteem, self-worth, competence and authority.

It is important to note that the highest number of significant differences in the results of personal anxiety in EG and CG was observed in sex and age subgroups 
Tab. 2. Complaints of ill pupils of secondary school age

\begin{tabular}{|c|c|c|c|c|c|c|c|}
\hline Groups & Grades & $\begin{array}{l}\text { difficulty in } \\
\text { exercising, } \\
\text { poor physical } \\
\text { performance }\end{array}$ & $\begin{array}{l}\text { health } \\
\text { condition } \\
\text { has recently } \\
\text { worsened }\end{array}$ & $\begin{array}{c}\text { daytime } \\
\text { sleepiness, } \\
\text { fatigue at the } \\
\text { end of the day }\end{array}$ & $\begin{array}{c}\text { unfounded } \\
\text { mood changes, } \\
\text { anxiety, } \\
\text { irritability }\end{array}$ & $\begin{array}{l}\text { spine and joint } \\
\text { pain during } \\
\text { prolonged } \\
\text { standing or } \\
\text { sitting } \\
\end{array}$ & $\begin{array}{l}\text { sight discomfort } \\
\text { during or after } \\
\text { lessons or } \\
\text { reduced visual } \\
\text { acuity } \\
\end{array}$ \\
\hline \multirow[t]{3}{*}{ EG } & 5 & 8,8 & 13,6 & 28,0 & 33,6 & 14,4 & 15,2 \\
\hline & 7 & 3,5 & 9,4 & 27,1 & 23,5 & 23,5 & 10,6 \\
\hline & 9 & 6,9 & 5,2 & 24,1 & 19,0 & 20,7 & 13,8 \\
\hline \multirow[t]{3}{*}{$\mathrm{CG}$} & 5 & 7,0 & 6,2 & 19,4 & 19,4 & 10,1 & 3,9 \\
\hline & 7 & 10,6 & 8,2 & 23,5 & 29,4 & 8,2 & 9,4 \\
\hline & 9 & 8,8 & 8,8 & 35,1 & 22,8 & 19,3 & 8,8 \\
\hline EG & \multirow[t]{2}{*}{ Average } & 6,4 & 9,4 & 26,4 & 25,4 & 19,5 & 13,2 \\
\hline CG & & 8,8 & 7,7 & 26,0 & 23,9 & 12,5 & 7,4 \\
\hline EG-CG & $\mathrm{p}=$ & - & - & - & - & 0,0257 & 0,0210 \\
\hline
\end{tabular}

of schoolchildren with health disorders (SMG). Thus, CG schoolgirls of the $5^{\text {th }}, 6^{\text {th }}$ and $9^{\text {th }}$ grades $(p<0.05)$, and CG schoolboys of the $9^{\text {th }}$ grade $(p<0.05)$ have indices of personal anxiety significantly higher than EG pupils, so its degree was assessed as higher: in EG - personal anxiety was moderate, whereas in CG - high. Therefore, schoolchildren who are training in terms of common PE lessons have lower rates of anxiety; to a great extent this is also true for schoolchildren with health disorders.

The analysis of health, activity and mood also showed the benefits of an inclusive model of PE in school as EG pupils' indices were significantly $(p<0,05-0,01)$ higher than in CG. Schoolchildren in PMG EG significantly more often (3 times) than in the CG demonstrated higher rates according to notions "well-being" and "mood", SMG pupils- according to notion "activity" (2 times) more often than in CG. Thus, we can state that students with health disorders, who trained in terms of common PE together with students of other medical groups, have subjective feelings of physiological or psychological state which are more comfortable, and their emotional reaction to the importance of PE in the context of advanced life programs, plans, expectations and interests are more favorable. Schoolchildren with health disorders during common PE lessons are more energetic, motivated, initiative and more active than those who were separated from physically well- prepared classmates. Therefore, we can state that for pupils with health disorders inclusive PE in secondary school is psychologically more comfortable than segregational one; the amount and intensity of interaction of children with physical and social environment, that is, their activity increases. This was confirmed by objective data on the volume of schoolchildren's MA (Table 3, 5).

In terms of basic and sedentary levels of MA no differences between CG pupils and EG pupils were observed (Table 3). This suggests that the way of PE lessons conduction has no effect on sleep duration and types of sedentary activities (reading, drawing, watching television, table and computer games).

Tab. 3. The volume of motor activity of secondary school age pupils

\begin{tabular}{|c|c|c|c|c|c|c|c|c|}
\hline \multirow[t]{2}{*}{ Groups } & \multirow[t]{2}{*}{ Grades } & \multicolumn{5}{|c|}{ Motor activity level, points } & \multirow{2}{*}{$\begin{array}{c}\text { MA } \\
\text { volume, } \\
\text { points }\end{array}$} & \multirow{2}{*}{$\begin{array}{l}\text { Energy consumption, } \\
\mathrm{kcal} / \mathrm{min}\end{array}$} \\
\hline & & base & sedentary & low & medium & high & & \\
\hline EG & 5 & 577,2 & 193,2 & 400,8 & 93,8 & 43,9 & 1806,9 & 2332,7 \\
\hline $\mathrm{CG}$ & 5 & 593,9 & 177,1 & 500,9 & 59,4 & 9,8 & 1690,4 & 2204,1 \\
\hline EG-CG & $\mathrm{p}=$ & 0,288 & 0,376 & 0,000 & 0,025 & 0,000 & 0,069 & 0,111 \\
\hline EG & 7 & 545,1 & 179,5 & 499,1 & 80,6 & 9,2 & 1726,7 & 2250,1 \\
\hline $\mathrm{CG}$ & 7 & 545,9 & 190.2 & 550,6 & 40,3 & 2,7 & 1645,0 & 2154,5 \\
\hline EG-CG & $\mathrm{p}=$ & 0,962 & 0,529 & 0,022 & 0,001 & 0,154 & 0,190 & 0,239 \\
\hline EG & 9 & 554,2 & 247,7 & 360,3 & 93,3 & 30,1 & 1741,3 & 2245,9 \\
\hline $\mathrm{CG}$ & 9 & 502,5 & 196,4 & 556,6 & 29,2 & 18,5 & 1702,9 & 2231,0 \\
\hline EG-CG & $\mathrm{p}=$ & 0,055 & 0,130 & 0,000 & 0,000 & 0,257 & 0,625 & 0,882 \\
\hline
\end{tabular}


However, in all age subgroups of CG knowledge volumes of low activity levels were significantly ( $p<0,05$ $0,000)$ higher. Instead, pupils in EG had got significantly higher $(\mathrm{p}<0,05-0,001)$ mid-level amounts of exercise activity, which included open-air sports entertainment of medium and low intensity, such as ice skating, roller skating, biking, etc. as well as helping parents about the house. Studying the structure of the favorite types of leisure activities it has been confirmed that children of EG are more willing to help parents $(12.8 \%, \mathrm{p}<0.01)$ and spend more time on walking $(10.9 \%, \mathrm{p}<0.01)$ i.e. household MA of applied (utilitarian) character is higher for them than for the CG students. It should be noted that the degree of divergence between CG and EG in terms of the average level of MA increased with age.

Vigorous activity volume during workouts in sports or choreographic clubs, active participation in PE lessons, inclusive PE lessons at secondary schools significantly $(p<0.05-0.001)$ increased their daily energy consumption and MA (due to relatively larger volume of high and medium MA levels and less volume of low MA as well as practically the same volume of sleep and sedentary activities).

High level MA revealed the similar tendency: volumes of high and medium MA level were larger $(p<0.000)$ in $C G$ in BMG whereas in PMG $(\mathrm{p}<0.05)$ and SMG $(p<0.05)$ - in EG. Since the conclusion is as follows: the participation of schoolchildren with health deviations in householding, walking time, frequency of sport events of low and medium intensity during leisure time such as iceskating, roller skating, biking, outdoor games, running hiking as well as in some special workouts, dancing clubs and sport competitions is higher if they attend inclusive PE lessons at secondary schools whereas in segregational

Tab. 4. Motor activity volume of average age schoolchildren

\begin{tabular}{|c|c|c|c|c|c|c|c|}
\hline \multirow{2}{*}{ groups } & \multicolumn{5}{|c|}{ Motor activity level, points } & \multirow{2}{*}{ MA volume, } \\
points & $\begin{array}{c}\text { Energy consumption, } \\
\mathrm{kcal} / \mathrm{min}\end{array}$ \\
\cline { 2 - 8 } & base & sedentary & low & medium & high & \\
\hline EG & 558.8 & 206.8 & 420.1 & 89.2 & 27.7 & 1758.3 & 2276.2 \\
\hline CG & 547.4 & 187.9 & 536.0 & 43.0 & 10.3 & 1679.4 & 2196.5 \\
\hline EG-CG, $\mathrm{p}=$ & 0.751 & 0.205 & 0.000 & 0.000 & 0.000 & 0.020 & 0.052 \\
\hline
\end{tabular}

Tab. 5. Motor activity volume of average age schoolchildren of different medical groups

\begin{tabular}{|c|c|c|c|c|c|c|c|c|}
\hline \multirow{2}{*}{ Groups } & \multirow{2}{*}{$\begin{array}{l}\text { medical } \\
\text { groups }\end{array}$} & \multicolumn{5}{|c|}{ Motor activity level, points } & \multirow{2}{*}{$\begin{array}{c}\text { MA volume, } \\
\text { points }\end{array}$} & \multirow{2}{*}{$\begin{array}{c}\text { Energy } \\
\text { consumption } \\
\mathrm{kcal} / \mathrm{min}\end{array}$} \\
\hline & & base & sedentary & low & medium & high & & \\
\hline EG & SMG & 416.3 & 186.3 & 480,1 & 49.6 & 7.5 & 1534.4 & 2006.7 \\
\hline $\mathrm{CG}$ & SMG & 526.3 & 173.8 & 466.5 & 22.5 & 0.0 & 1471.1 & 1924.9 \\
\hline EG & PMG & 552.0 & 192.8 & 419.9 & 68.6 & 16.7 & 1642.3 & 2131.1 \\
\hline $\mathrm{CG}$ & PMG & 555.0 & 191.5 & 572.1 & 51.7 & 4.4 & 1738.5 & 2275.8 \\
\hline EG & $\mathrm{BMG}$ & 566.4 & 211.2 & 500.8 & 39.5 & 9.7 & 1673.5 & 2184.0 \\
\hline CG & BMG & 551.8 & 186.7 & 421.9 & 107.2 & 32.7 & 1785.6 & 2309.7 \\
\hline \multirow[t]{6}{*}{ EG-CG } & SMG, $\%$ & -110.0 & 12.5 & 13.6 & 27.1 & 7.5 & 63.3 & 81.8 \\
\hline & $\mathrm{p}=$ & 0,399 & 0.753 & 0.899 & 0.349 & 0.050 & 0.708 & 0.716 \\
\hline & PMG, $\%$ & -3.005 & 1.292 & -152.230 & 16.877 & 12.381 & -95.918 & -144.632 \\
\hline & $\mathrm{p}=$ & 0.152 & 0.852 & 0.000 & 0.416 & 0.023 & 0.268 & 0.206 \\
\hline & $\mathrm{BMG}, \%$ & 14.670 & 24.469 & 78.894 & -67.700 & -22.969 & -112.089 & -125.673 \\
\hline & $\mathrm{p}=$ & 0.257 & 0.163 & 0.000 & 0.000 & 0.000 & 0.044 & 0.080 \\
\hline
\end{tabular}

sporting competitions, intensive games, running, hiking, etc. were larger in EG ( $5^{\text {th }}$ grade pupils - significantly larger, - at $\mathrm{p}<0,000)$. Though the general MA volumes (estimated in points) and energy consumption in age groups demonstrated the tendency to prevailing only in EG pupils but after combining those into one group (Table 4) these and other intergroup indices attained statistic trustworthiness. Thus, the schoolchildren attending
PE lessons the conditions for increasing of high and medium MA levels are favourable for practically healthy schoolchildren.

Having generalized the tables 4 and 5 data we can state that the daily MA of pupils with health deviations in terms of inclusive PE lessons (SMG and PMG) is higher than in segregational conditions. Since only practically healthy schoolchildren have higher MA of medium level 
in $\mathrm{CG}$ at the same time two other groups containing pupils with health disorders revealed the tend to prevailing of medium and high MA level in EG. That's why we can definitely affirm that due to indices of pupils with health deviations the general volume of MA medium level of EG schoolchildren's activity left significantly behind the CG pupils' MA volume.

Thus, the generalization of the obtained data allows stating that inclusive PE is effective, since in such terms we can observe the tendency to decreasing of complaints of different medical groups schoolchildren as for poor health, a larger number of individuals have situational anxiety; the indices of well-being, activity and mood are significantly $(\mathrm{p}<0.05-0.01)$ higher, schoolchildren's everyday MA is higher $(\mathrm{p}<0.05-$ 0.001 ); slightly higher (in $5^{\text {th }}$ grade definitely $\mathrm{p}<0.000$ higher) are volumes of purposeful training sessions; since due to larger high and medium MA levels, substantial leaving behind the low activity level and practically the same volumes of sleep and sedentary activities the energy consumption of schoolchildren in inclusive conditions prevails.

Inclusive PE is more effective for the schoolchildren with health deviations since they demonstrate lower indices of anxiety, better well-being and mood, higher (social and physical) activity $-(\mathrm{p}<0.05-0.01)$; volumes of MA are increasing.

Segregational $\mathrm{PE}$ is more favourable for the practically healthy schoolchildren since it contributes to increasing of high and medium MA volumes $(\mathrm{p}<0.000)$ that is workouts at sport clubs and individual forms of leisure time.

In segregational terms of PE lesson schoolchildren have less complaints of muscular-skeleton system and sight impairment but later the complaints are more frequent and it was observed that practically healthy schoolchildren $(\mathrm{p}<0.01)$ have symptoms of psychic disorders.

\section{Conclusions}

1. A number of complaints connected with poor health among schoolchildren in terms of inclusive PE is practically the same as among pupils who attend segregational PE lessons. Later the number of pupils who complain of poor health decreases in terms of common PE lessons whereas in segregational conditions one can observe a contrary tend. Particular warning is caused by schoolchildren's frequent complaints of neuro-psychic deviations (35.1\% and 29.4\%) in segregational terms of PE lessons that threaten with possible development of psychosomatic diseases. The established tends affirm higher efficiency of inclusive PE.
2. Inclusive PE lessons are less traumatic than segregational ones since the high anxiety indices in such terms are available rarely $(\mathrm{p}<0.05)$, low anxiety indices -more often; wellness, activity and mood feelings are higher $(\mathrm{p}<0.05-0.01)$. Positive psychic changes are observed in every pupil but they are the most significant in terms of inclusive terms of training of schoolchildren with health deviations: PE lessons are taken more positively by schoolchildren who are calmer and more motivated and active because of safety feeling.

3. The schoolchildren in terms of inclusive PE at secondary schools substantially $(p<0.05-0.001)$ demonstrate daily energy consumption due to MA increasing (because of relatively larger volumes of high and medium MA levels and less volumes of low activity level and practically the same volumes of sleep and sedentary activities). Larger volumes of everyday activities and purposeful sporting activities affirm the advantages of inclusive PE at secondary schools.

Established indices of mental development, volumes and type of schoolchildren's MA who trained in terms of inclusion and segregation allow affirming that inclusive model of PE is more effective than segregational one, especially for the schoolchildren with health deviations; whereas in segregational conditions the daily MA of practically healthy schoolchildren is even higher.

\section{References}

1. Khohlova LA. Necotoryye factory, vliyayushchije na sostoyuanije zdorovja; [Some Factors Influencing Health] Fisichescoje vospitanije studentov; N4; 2010; S.70-73. [Electronic resource]. - Mode of access: http://nbuv.gov.ua/ portal/Soc_Gum/PhVSTS/2010_4/10klaahs.pdf

2. Sutula AV. Socialni factory, yaki obumovlyyut porushennya postavy u shkolyariv [Electronic resource]. Режим доступу: http://www.nbuv.gov.ua/portal/soc_gum/ snsv/2011_1/11suafts.pdf

3. Sered ukraiinskyh shkolyariv najposhyrenishi zahvoryuvennya nervovoi systemy ta psyhiky [Electronic resource]. - Mode of access: http://ukped.com/ novini/tse-tsikavo/2457-sered-ukrayinskih-shkoljarivnajposhirenishi-zahvorjuvannja-nervovoyi-sistemi-tapsihiki.html

4. Atestat smertnosti [Electronic resource]. http://versia.ru/ articles/2011/aug/22/podorvannoe_zdorovie_shkolnikov

5. Shuvalova VS. Zdorovye uchashchihsya I obrazovatelnaya sreda [Electronic resource] http://gendocs.ru/ docs/29/28004/conv_22/file22.pdf

6. Vovk LV. Biolohicheskiye factory narushenij psihicheskogo zdorovya I ih vliyaniye na zdorovyj obraz zhizni studentov specialnoj meditcinskoj grupy; Pedagogika, psihologiya 
ta medico-biologichni problem fizuchnogo vyhovannya I sportu; 2011; N4: 39-42.

7. Hihiyenichna otcinka vykorystannya zdorovyaformuyuchoho potentcialu navchalnyh zakladiv [Electronic resource] http://www.nbuv.gov.ua/portal/chem_biol/environment/2008_3/2008_3/46-0053.pdf
8 Cardon G, De Clercq D, De Bourdeaudhuij I. Back education efficacy in elementary schoolchildren: a one-year follow-up study. Spine 2002; 27; 299-305.

9. Viry P, Creveuil C, Marcelli C. Nonspecific back pain in children: a search for associated factors in 14-year-old schoolchildren; Revue du Rhumatisme (English Ed) 1999; 66: 437-445. 